\title{
Alarmins and innate lymphoid cells 2 activation: a common pathogenetic link connecting RSV bronchiolitis and later wheezing/asthma?
}

\author{
Giovanni Rossi ${ }^{1}$, Stefania Ballarini ${ }^{2}$, Pietro Salvati ${ }^{1}$, Oliviero Sacco $^{3}$, and Andrew Colin ${ }^{4}$ \\ ${ }^{1}$ Ospedale Giannina Gaslini \\ ${ }^{2}$ University of Perugia School of Medicine and Surgery \\ ${ }^{3}$ Istituto Giannina Gaslini \\ ${ }^{4}$ University of Miami
}

March 8, 2022

\begin{abstract}
Severe RSV infection in infancy is associated with increased risk of recurrent wheezing in childhood. Both acute and long-term alterations in airway functions are thought to be related to inefficient anti-viral immune response. The airway epithelium, the first target of respiratory syncytial virus (RSV), normally acts as an immunological barrier able to elicit an effective immune reaction but may also be programmed to directly promote a Th2 response, independently from Th2 lymphocyte involvement. Recognition of RSV transcripts and viral replication intermediates by bronchial epithelial cells brings about release of TSLP, IL33, HMGB1 and IL-25, dubbed "alarmins". These epithelial cell-derived proteins are particularly effective in stimulating innate lymphoid cells 2 (ILC2) to release IL-4, IL-5, and IL-13. ILC2, reflect the innate counterparts of Th2 cells and, when activate, are potent promoters of airway inflammation and hyperresponsiveness in RSV bronchiolitis and childhood wheezing/asthma. Long-term epithelial progenitors or persistent epigenetic modifications of the airway epithelium following RSV infection, may play a pathogenetic role in the short and long-term increased susceptibility to obstructive lung diseases in response to RSV in the young. Additionally, ILC2 function may be further regulated by RSV-induced changes in gut microbiota community composition that can be associated with disease severity in infants. A better understanding of the alarmin-ILC interactions in childhood might provide insights into the mechanisms characterizing these immune-mediated diseases and indicate new targets for prevention and therapeutic interventions.
\end{abstract}

\section{INTRODUCTION}

Respiratory syncytial virus (RSV) is a common and highly contagious pathogen inducing acute respiratory tract infections in infants [1]. Although in many cases symptoms remain mild, a subset of individuals develops severe RSV-associated bronchiolitis [1,2]. The severity of the disease in infancy, thought to be related to the physiological immaturity of the immune system, is also linked to an increased risk of recurrent wheezing in later life [3,4]. This phenomenon is not always associated to atopic sensitization but is thought to be related to long-term immune response alterations and neuromuscular tone instability in the airways [3,4]. The airway epithelium, the primary target of RSV infection, is an important component of the antiviral response, acting both as a physical fence and as an immunological barrier able to elicit inflammatory and immune mediate responses [5]. Recognition of RSV transcripts and viral replication intermediates by bronchial epithelial cells (BECs) induces the production of type I and type III IFNs and other cytokines, all geared to mount an effective antiviral reaction $[3,5]$. However, BECs may also be programmed to release mediators that activate a Th2 immune response, aggravating the infection, and contributing to airway damage [6]. These mediators include thymic stromal lymphopoietin (TSLP), IL-33, the high mobility group box 1 (HMGB1) and IL-25 
[6,7]. Often characterized as "alarmins", these epithelial cell-derived proteins regulate a broad spectrum of immune cell populations and are particularly potent in eliciting and activating type 2 innate lymphoid cells (ILC2) in a variety of lung disorders, including RSV bronchiolitis and recurrent wheezing/asthma in childhood [7-12]. It is therefore possible that, following a first severe respiratory infection in early life, long-term epithelial cell progenitors or persistent epigenetic modifications leading to alarmin-induced ILC2 activation may be involved in the ongoing increased susceptibility to obstructive lung diseases [13]. Through DNA methylation and histone ubiquitination, RSV can induce epigenetic modifications in BECs that favor Th2 responses [14], promoting post bronchiolitis wheezing [15]. In RSV-infected BEC cultures, upregulation of the expression of the epigenetic regulator histone deacetylase2 (HDAC2) was associated with increased viral replication and production of pro-inflammatory cytokine, and oxidative stress-related molecules [16]. Evaluating cells obtained by nasal brushing at age 6 in preterm infants, who received RSV immunoprophylaxis with palivizumab or placebo during their first RSV season, demonstrated that palivizumab had global and persistent effects on nasal DNA methylation patterns, relevant innate immune viral response, and viral budding genes [17]. These data suggest that RSV-induced epigenetic modification in airway cell functions could represent a common pathogenetic imprint in severe RSV bronchiolitis and subsequent recurrent wheezing/asthma in childhood. Finally, ILC2 activation and disease severity can also be regulated through the production of alarmins by RSV-induced gut microbiome dysbiosis, as shown in infants with bronchiolitis [18].

\section{THE INNATE LYMPHOID CELLS (ILC)}

To maintain tissue homeostasis and integrity, lungs are protected by a complex network of highly specialized immune cells that include ILC [10,11]. Creating a first-line defense system, these cells play diverse roles in inflammation and infection, including promotion of innate immunity, acquisition of adaptive immunity, maintenance of epithelial barrier function and tissue repair [9-11,19]. Being tissue-resident elements, ILC tend to proliferate locally following environmental challenges [9-11,18]. However, there is increasing evidence that, in inflammatory disorders, ILC migrating from other organs could contribute to the expansion and the modulation of the local cell pools [19-21]. Based on distinctive phenotypic markers, transcription factors and effector function, ILC can be divided into three subsets: ILC1, ILC2 and ILC3. These ILC subsets share many phenotypic, morphological, and functional features with CD4 ${ }^{+}$Th1, Th2 and Th17 cells [9,10,18-21]. However, in contrast with T-cells, regulated by antigen presentation via antigen-presenting cells, ILC are mainly regulated by soluble factors such as cytokines, chemokines, neuronal factors, and other inflammatory mediators [22-25]. ILC1 express the transcription factor Tbx21 and, in response to IL-12, IL-15, and IL-18, produce IFN- $\gamma$ and TNF- $\alpha$ (figure 1A). ILC2 express the transcription factor GATA-3 and, in response to the alarmins TSLP, IL-25, HMGB1 and IL-33, secrete the classical type 2 effector cytokines IL-4, IL-5 and IL-13 [26]. ILC3 express the transcription factor ROR $\gamma t$ and, in response to IL-23 and IL-1 $\beta$, release IL-17 and IL-22 [20,27]. ILC subsets are not 'fixed' and exhibit considerable functional plasticity depending on the inflammatory milieu [28]. For example, ILC2 can transdifferentiate into ILC1 or ILC3 in response to IL-1 $\beta$, IL-12 and TGF- $\beta$ but this switch is bi-directional, as these transdifferentiations can be reversed by IL-4 (figure 1B) [28]. Additionally, TLR-2 activation can promote the production of the Th2 cytokines IL-5 and IL-13 by ILC3, which suggests that these cells might be able to differentiate into ILC2 (figure 1C) [29]. Finally early reports suggest that ILC2 are significantly more potent than Th2 cells, producing greater than 10-fold the amount of Th2 cytokines on a per-cell basis [30], explaining why ILC2 may have a significant role in several inflammatory disorders and, possibly, in reduced response to corticosteroids. Increased proportions of sputum and blood ILC2 were detected in children with severe therapy-resistant asthma [8]. In these children ILC2s were significantly reducedin vitro when cultured with steroids and in vivo following intramuscular triamcinolone. Systemic corticosteroids, but not maintenance inhaled steroids, resulted in improved symptom control and exacerbations [8]

\section{ALARMINS, ILC ACTIVATION IN RSV INFECTION AND WHEEZING/ASTHMA}

In response to RSV, other viruses as well as allergens and other triggers involved in wheezing/asthma pathogenesis, airway epithelium can directly stimulate ILC2 to release IL-4, IL-5, and IL-13 through the 
release of alarmins (figure 2). IL-4 drives Th2 cell differentiation and promotes B cell antibody class switch to IgE-producing-plasma cells [31-33]. IL-5 recruits and enhances survival of eosinophils, major component of the Th2 inflammatory infiltrates [34,35]. IL-13 increases goblet cell mucin expression and development of airway hyperresponsiveness [36]. Thus, the alarmins IL-33, IL-25, TSLP and HMGB1, through ILC2 activation, can play a significant role in promoting the progression of Th2 type response in infants with RSV bronchiolitis and in increasing the risk of developing recurrent wheezing/asthma and, possibly, susceptibility to allergic exacerbation in later life [37].

\subsection{Thymic Stromal Lymphopoietin (TSLP)}

Clinical and experimental studies showed that TSLP, a cytokine primarily expressed by epithelial cells, is induced by RSV infections [39,40]. Evaluating infants hospitalized with bronchiolitis (70\% due to RSV), and matched healthy infants at their primary care appointments, García-García et al showed upregulation of TSLP levels in nasopharyngeal aspirates of the bronchiolitis group [41]. Among RSV-infected infants, those who needed ICU admission presented more frequently detectable and higher TSLP concentrations. Moreover, when primary BEC cultures obtained by cytologic brushings from children were exposed to RSV, a rapid and significantly higher TSLP production was detected in asthmatics, as compared to healthy control [42]. In wild-type mice, TSLP levels were increased 12 hours after infection and significant increase in IL13-producing ILC2 and in lung IL-13 levels was observed on day 4 after infection [43]. TSLPR knockout (KO) mice did not mount an IL-13-producing ILC2 response to RSV infection, displayed reduced lung IL-13 protein levels, decreased airway mucus and hyperreactivity, as compare with wild-type mice [43]. Gender differences may also impact on TSLP-induced immune alterations following early-life RSV infection [44]. As compared to neonatal female mice, neonatal male mice infected with RSV exhibited higher viral loads and lower IFN $\beta$ production and delayed infection resolution, on day 4 post-infection. At 4 weeks post-infection, neonatal male but not female mice, had higher TSLP and IL-33 levels in their lungs, increased IL-13 gene expression in lung ILC2, airway reactivity and mucus secretion [44]. These changes in male mice were associated with an increased susceptibility to allergic exacerbation upon allergen challenge at 4 weeks of age [44].

\subsection{Interleukin-33 (IL-33)}

Binding to and signaling through its ST2 receptor, IL-33 drives the production of Th2-associated cytokines in asthma and other allergic diseases but also acts as ILC2 activator during viral infections [45-47]. In infants $<2$ years of age, hospitalized with bronchiolitis during the RSV season, increased amounts of IL-33 were detected in the upper airways, more frequently in infants with RSV and HRV coinfections than in those with either infection alone [41]. In BALB/c mice intranasal inoculation with RSV induced IL-33 and IL-13 production, and increased eosinophil recruitment in the lung [48]. In these animals, production of IL-13 occurred involving the IL-33/ST2 pathway, since incubation of lung cells with anti-ST2 antibody diminished IL-13-producing cell frequency [48]. To further determine the role of IL-33 in activating ILC2 during RSV infection, a study on wild-type and IL-33 KO mice was performed [43]. On day 4 after infection, both wild-type and IL-33 KO mice showed a significant inflammatory response to RSV, with a significant and similar increase in the total numbers of lung IL- $13^{+}$ILC2. However, IL-13 concentrations were significantly lower in RSV-infected IL-33 KO mice than in RSV-infected wild-type mice [43], highlighting the role for IL-33 in ILC2 activation. Age-variable effects of alarmins on ILC2 can also explain why chronological age at time of infection, is an important risk factor for severe RSV bronchiolitis [1]. In the lungs of neonatal, but not of adult mice, infection with RSV induced a rapid IL-33 expression and an increase in ILC2 numbers [49]. Administration of IL-33 to adult mice during RSV infection induced lung disease, whereas blocking IL-33 with antibodies during infection or using IL-33 receptor KO neonatal mice inhibited Th2 inflammation, airway hyperresponsiveness and mucus overproduction [49]. In this study, wild-type mice were reinfected with RSV at 4 weeks post-primary infection. In neonatal mice, neutralizing IL-33 with antibodies during primary infection resulted in significantly reductions of $\mathrm{Th} 2$ inflammation and airway hyperresponsiveness following RSV reinfection [49]. Moreover, adoptive transfer of ILC2 from donor wild-type mice or administration of IL33 to IL-33-deficient mice was crucial for the development of airway inflammation and hyperresponsiveness 
following RSV infection [50].

\subsection{High Mobility Group Box 1 (HMGB1)}

HMGB1 is one of the most important damage-associated molecular patters acting as a proinflammatory cytokine [51]. It promotes and perpetuate the immune responses in infectious and non-infectious inflammatory diseases [51,52]. HMGB1 levels were found to be elevated in nasopharyngeal aspirates of hospitalized infants with RSV bronchiolitis, and significantly higher in the moderate-severe group [53]. In immortalized and primary human BECs, the RSV-induced HMGB1 expression was decreased when the cultures were exposed to glycyrrhizin, a specific HMGB1 inhibitor [54]. A dose dependent decreased of the HMGB1 positive cell numbers was also detected, associated with significant reduction in viral replication [54]. In BALB/c mice infected with RSV, type 2 cytokines IL-4, IL-5, and IL-13 were found to be gradually increased in bronchoalveolar lavage from days 14 to 30 post-infection [53]. HMGB1 expression was localized to bronchiolar low columnar/cuboidal cells, found in the small airways. Treatment with anti-HMGB1 antibody significantly reduced HMGB1 levels and IL-4, IL-5, and IL-13 concentrations, suppressed the inflammatory cell infiltration and decreased the severity scores [53]. In IRF7-deficient $\left({ }^{--}\right)$mice, characterized by defective antiviral immunity, infection with PVM (a mouse-specific pathogen belonging to the same genus as RSV) promoted epithelial HMGB1 expression, associated with an increase in the numbers of IL-13-producing ILC2 [55]. Increase of both the levels of the potent airway smooth muscle (ASM) mitogen TGF- $\beta$ and ASM cell proliferation was also detected, suggesting that ASM alterations could initiate the response to a severe RSV infection in early-life [55]. Anti-HMGB1 antibodies ablated lung ILC2 numbers and ASM growth in vivo , and inhibited ILC2-mediated ASM cell proliferation in a co-culture model [55]. Finally, several other mouse studies using different inducible models of asthma demonstrated that anti-HMGB1 antibody treatment reduced IL-4, IL-5, and IL-13, as well as airway mucus compared to control antibody or mice not given antibody [56,57].

\subsection{Interleukin-25 (IL-25)}

IL-25 is a member of the interleukin-17 cytokine family that recognizes a receptor composed of IL-17RB and IL-17RA subunits [58]. IL-17RB receptor is mainly expressed on ILC2, and its activation is involved in type 2 effector response [58-61]. In C57BL/6J mice, exposure to RSV induced the expression of IL-25 and IL-17RB lung transcripts and of other potentially pathogenic cytokines, including IL-13 [61]. Treatment with an anti-IL-25 antibody significantly reduced Th2 cytokine production, mucus-associated gob5 gene expression and airway hyperresponsiveness. Moreover, IL-17RB ${ }^{-/-}$mice showed increased clearance of the virus and diminished pathology [61]. In a different set of experiments, IL-17RB ${ }^{-/-}$mice were sensitized to allergen, infected with RSV during the active allergic responses, and then challenged with allergen [62]. As compared to wild-type mice, decreased inflammatory response, cytokine production and IL-13 and gob5 gene expression was detected in IL-17RB $/$ - mice, possibly reflecting enhanced clearance of RSV, leading to decreased immune activation [61]. Immune and morphological responses to RSV infection were also evaluated in wild-type and NK cell-depleted BALB/c mice [62]. NK cells play a critical role in the development of an effector immune response in RSV infection [63]. Depletion of NK cells led to increased IL-25 expression in the respiratory epithelium, higher IL-4, IL-13 and eotaxin lung mRNA levels and higher serum IgE, tissue eosinophil numbers and mucus-secreting cells. This increased Th2 pathology was reflected in a delayed viral clearance in the later stages of infection [61]. RSV-induced Th2 responses were IL-25 dependent. Treatment of NK-depleted mice with anti-IL-25 antibodies led to attenuation of the Th2 cell responses, suppression of inflammation and histopathological changes in the lungs [62].

\section{GUT MICROBIOTA, RSV INFECTION, ALARMINS AND ILC2}

Gut microbiota composition might affect the severity of respiratory virus infections, but the interaction can be bidirectional, since infections can induce gut dysbiosis [64,65]. The high concentration of microorganismand pathogen-associated molecular patterns physiologically present in the gut and the huge amounts of cytokines and chemokines produced during dysbiosis can activate local ILC that can then migrate to other sites of the body [19-21]. In an integrated microbiota dysbiosis mice model, it was demonstrated that gut 
microbiota can modulate ILC2 directional migration to the lung via regulation of select cytokines [66]. In these mice, Proteobacteriaabundance was associated with increased IL-33 production which promoted ILC2 migration and accumulation in the lung. Blocking the IL-33 receptor with anti-ST2 antibodies, abolished the observed increased percentages of lung ILC2 in this animal model [65]. Moreover, tissue and circulating ILC2 can recognize microbial ligands through their TLR, and directly produce a variety of cytokines, chemokines which can fight or promote infections [19-21, 67-70]. In stool samples collected from infants hospitalized during a bronchiolitis season, four microbiota profiles were detected:Escherichia -dominant, Bifidobacterium -dominant,Enterobacter / Veillonella -dominant, andBacteroides -dominant [71]. The proportion of infants with bronchiolitis (related to RSV infection in $65 \%$ of them) was lowest in the Enterobacter / Veillonella -dominant profile and highest in the Bacteroides -dominant profile [71]. To determine whether a specific gut microbial profile could be associated with RSV severity, stool samples were collected in 95 infants during an RSV season: 37 were healthy babies and 58 were hospitalized with RSV bronchiolitis [18]. Out of the RSV positive infants, 53 remained in the pediatric ward and 5 later moved to the pediatric intensive care unit. There was a significant enrichment inBacteroides, and a decrease in Firmicutes in RSV infants vs. healthy controls. In addition, infants with severe RSV disease had slightly lower alpha diversity (richness and evenness of the bacterial community) of the gut microbiota compared to infants with moderate RSV and controls. Beta diversity (overall microbial composition) was significantly different between all RSV patients compared to controls [18]. These results were confirmed in BALB/mice in which, after RSV infection, showed

a significant increase in the relative abundance of Bacteroidetes and a corresponding decrease in Firmicutes was detected (figure 3A) [72]. Interestingly, many members of the Bacteroidetes phylum use mucus as an energy source [73] and Muc5ac mucin levels were significantly increased in the airways and colon of RSVinfected mice, but not in control mice. Changes in gut microbiota composition following RSV infection may also indirectly regulate ILC2 function through the production of alarmins. 6-to-8-week-old BALB/c male mice were randomly divided into a control (CON) group, an ovalbumin (OVA) sensitized group, and an OVA + RSV group [73]. Compared with the CON group, the OVA group had lower abundance of bothBacteroidetes and Firmicutes (figure 3B), whereas higher abundance of these phyla was detected in the OVA + RSV group, compared with the OVA group (figure 3C). RSV-infected asthmatic mice had increased expression of IL-25 and IL-33 and of the Th2 cytokines IL-4, IL-5, and IL-13 [74]. Prevotellaceae_NK4A136 -group, which belongs to the Bacteroides species, was significantly associated with IgE, IL-33, IL-25, IL5, and IL-13 levels, whereasLachnospiraceae_NK4A136_ group which belongs to theFirmicutes species, was significantly associated with IgE and IL-33 levels [74]. Aggravation of bronchial hyperresponsiveness to methacholine and airway inflammation was observed in asthmatic mice following RSV infection-induced alteration of gut microbiota. Interestingly, in a study comparing children with recurrent respiratory tract infections (RRTI) and a healthy control group, distinct gut bacterial community structures between the groups were observed with an enrichment in Bacteroidetes in the RRTI group [75]. Whether probiotics and/or bacterial derived products, potentially involved in immune training, could affect gut dysbiosis, prevent GIT epithelial dysfunction and the related negative influence on the immune system is an interesting hypothesis that needs to be adequately addressed and demonstrated [76,77].

\section{CONCLUSIONS}

In response to RSV infection BECs can release alarmins, mediators effective in stimulating ILC2 to produce Th2 cytokines, promoters of airway inflammation and hyperresponsiveness in RSV infection. Long-term epithelial progenitors or persistent epigenetic modifications of BECs following RSV bronchiolitis in infants, may play a pathogenetic role on the ongoing increased susceptibility to obstructive lung diseases in childhood. Experimental studies suggest that alarmin-induced ILC2 activation, which can be modulated by gut dysbiosis, may represent a common pathogenetic imprint in RSV bronchiolitis and later recurrent wheezing. A better understanding of the pathways involved in alarmin production by airway epithelial cells and on the alarmin-ILC2 interactions might provide insights into the mechanisms characterizing these immune-mediated diseases. The position of alarmins at the top of the inflammatory cascade makes them a promising prevention and therapeutic targets.

CONFLICT OF INTEREST. The author declares no conflicts of interest. 
ETHICAL APPROVAL. Because of category of the manuscript, a review, approval from the ethical committee was not necessary.

Data availability statement. Data sharing is not applicable to this article as no new data were created or analyzed in this manuscript.

\section{References}

1. Meissner HC. Viral bronchiolitis in children. N Engl J Med 2016;374:62-72.

2. Nair H, Nokes DJ, Gessner BD, et al. Global burden of acute lower respiratory infections due to respiratory syncytial virus in young children: a systematic review and meta-analysis. Lancet 2010: 375: $1545-55$.

3. Rossi GA, Colin AA. Respiratory syncytial virus-Host interaction in the pathogenesis of bronchiolitis and its impact on respiratory morbidity in later life. Pediatr Allergy Immunol. 2017;28:320-331.

4. Régnier SA, Huels J. Association between respiratory syncytial virus hospitalizations in infants and respiratory sequelae: systematic review and meta-analysis. Pediatr Infect Dis J. 2013;32:820-6.

5. Glaser L, Coulter PJ, Shields M, Touzelet O, Power UF, Broadbent L. Airway Epithelial Derived Cytokines and Chemokines and Their Role in the Immune Response to Respiratory Syncytial Virus Infection. Pathogens. 2019;8:106.

6. Roan F, Obata-Ninomiya K, Ziegler SF. Epithelial cell-derived cytokines: more than just signaling the alarm. J Clin Invest. 2019;129:1441-1451.

7. Panda SK, Colonna M. Innate Lymphoid Cells in Mucosal Immunity. Front Immunol. 2019;10:861.

8. Nagakumar P, Puttur F, Gregory LG, Denney L, Fleming L, Bush A, Lloyd CM, Saglani S. Pulmonary type-2 innate lymphoid cells in paediatric severe asthma: phenotype and response to steroids. Eur Respir J. 2019;54:1801809

9. Hsu AT, Gottschalk TA, Tsantikos E, Hibbs ML. The Role of Innate Lymphoid Cells in Chronic Respiratory Diseases. Front Immunol. 2021;12:733324.

10. Borger JG, Lau M, Hibbs ML. The Influence of Innate Lymphoid Cells and Unconventional T Cells in Chronic Inflammatory Lung Disease. Front Immunol. 2019;10:1597.

11. Norlander AE, Peebles RS Jr. Innate Type 2 Responses to Respiratory Syncytial Virus Infection. Viruses. 2020;12(5):521.

12. Sastre B, García-García ML, Cañas JA, Calvo C, Rodrigo-Muñoz JM, Casas I, Mahíllo-Fernández I, Del Pozo V. Bronchiolitis and recurrent wheezing are distinguished by type 2 innate lymphoid cells and immune response. Pediatr Allergy Immunol. 2021;32:51-59.

13. Caixia L, Yang X, Yurong T, Xiaoqun Q. Involvement of epigenetic modification in epithelial immune responses during respiratory syncytial virus infection. Microb Pathog. 2019;130:186-189.

14. Wang L, Wu G, Qin X, Ma Q, Zhou Y, Liu S, Tan Y. Expression of Nodal on Bronchial Epithelial Cells Influenced by Lung Microbes Through DNA Methylation Modulates the Differentiation of T-Helper Cells. Cell Physiol Biochem. 2015;37:2012-22.

15. Tan YR, Peng D, Chen CM, Qin XQ: Nonstructural protein-1 of respiratory syncytial virus regulates HOX gene expression through interacting with histone. Mol Biol Rep 2013;40:675-679.

16. Feng Q, Su Z, Song S, Xu H, Zhang B, Yi L, Tian M, Wang H. Histone deacetylase inhibitors suppress RSV infection and alleviate virus-induced airway inflammation. Int J Mol Med. 2016;38:812-22.

17. Xu CJ, Scheltema NM, Qi C, Vedder R, Klein LBC, Nibbelke EE, van der Ent CK, Bont LJ, Koppelman GH. Infant RSV immunoprophylaxis changes nasal epithelial DNA methylation at 6 years of age. Pediatr Pulmonol. 2021;56:3822-3831.

18. Harding JN, Siefker D, Vu L, You D, DeVincenzo J, Pierre JF, Cormier SA. Altered gut microbiota in infants is associated with respiratory syncytial virus disease severity. BMC Microbiol. 2020 Jun $1 ; 20(1): 140$.

19. Klose CSN, Artis D. Innate lymphoid cells control signaling circuits to regulate tissue-specific immunity. Cell Res. 2020;30:475-491.

20. Willinger T. Metabolic Control of Innate Lymphoid Cell Migration. Front Immunol. 2019 Aug $22 ; 10: 2010$. 
21. Lim AI, Li Y, Lopez-Lastra S, Stadhouders R, Paul F, Casrouge A, et al. Systemic Human ILC Precursors Provide a Substrate for Tissue ILC Differentiation. Cell. 2017; 168:1086-100.e10.

22. Marashian SM, Mortaz E, Jamaati HR, Alavi-Moghaddam M, Kiani A, Abedini A, Garssen J, Adcock IM, Velayati AA. Role of Innate Lymphoid Cells in Lung Disease. Iran J Allergy Asthma Immunol. 2015;14:346-60.

23. Spits H, Cupedo T. Innate lymphoid cells: emerging insights in development, lineage relationships, and function. Annu Rev Immunol. 2012;30:647-75.

24. Fan X, Rudensky AY. Hallmarks of Tissue-Resident Lymphocytes. Cell. 2016;164:1198-1211.

25. Mjösberg J, Spits H. Human innate lymphoid cells. J Allergy Clin Immunol. 2016;138(5):1265-1276.

26. Eberl G, Colonna M, Di Santo JP, McKenzie AN (2015) Innate lymphoid cells: a new paradigm in immunology. Science 348: aaa6566.

27. Bartemes KR, Iijima K, Kobayashi T, Kephart GM, McKenzie AN, Kita H. IL-33-responsive lineageCD25+CD44hi lymphoid cells mediate innate type 2 immunity and allergic inflammation in the lungs. J Immunol 2012; 188:1503-13.

28. Guo L, Junttila IS, Paul WE. Cytokine-induced cytokine production by conventional and innate lymphoid cells. Trends Immunol 2012; 33:598-606.

29. Bal SM, Golebski K, Spits H. Plasticity of innate lymphoid cell subsets. Nat Rev Immunol. 2020;20:552565 .

30. Crellin NK, Trifari S, Kaplan CD, Satoh-Takayama N, Di Santo JP, Spits H. Regulation of cytokine secretion in human CD127(+) LTi-like innate lymphoid cells by Toll-like receptor 2. Immunity. 2010;33:752-64.

31. Klein Wolterink RG, Kleinjan A, van Nimwegen M, Bergen I, de Bruijn M, Levani Y, Hendriks RW. Pulmonary innate lymphoid cells are major producers of IL-5 and IL-13 in murine models of allergic asthma. Eur J Immunol. 2012;42:1106-16.

32. Lambert L, Sagfors AM, Openshaw PJ, Culley FJ. Immunity to RSV in Early-Life. Front Immunol. $2014 ; 5: 466$.,

33. Steinke JW, Borish L. Th2 cytokines and asthma. Interleukin-4: its role in the pathogenesis of asthma, and targeting it for asthma treatment with interleukin-4 receptor antagonists. Respir Res. 2001;2:66-70.

34. Cohn L, Homer RJ, Marinov A, Rankin J, Bottomly K. Induction of airway mucus production By T helper 2 (Th2) cells: a critical role for interleukin 4 in cell recruitment but not mucus production. J Exp Med. 1997;186:1737-47.

35. Thurau AM, Streckert HJ, Rieger CH, Schauer U. Increased number of T cells committed to IL-5 production after respiratory syncytial virus (RSV) infection of human mononuclear cells in vitro. Clin Exp Immunol. 1998;113:450-5.

36. Garofalo R, Kimpen JL, Welliver RC, Ogra PL. Eosinophil degranulation in the respiratory tract during naturally acquired respiratory syncytial virus infection. J Pediatr. 1992;120:28-32.

37. Zhu Z, Homer RJ, Wang Z, Chen Q, Geba GP, Wang J, Zhang Y, Elias JA. Pulmonary expression of interleukin-13 causes inflammation, mucus hypersecretion, subepithelial fibrosis, physiologic abnormalities, and eotaxin production. J Clin Invest. 1999;103:779-88.

38. Webb DC, McKenzie AN, Koskinen AM, Yang M, Mattes J, Foster PS. Integrated signals between IL-13, IL-4, and IL-5 regulate airways hyperreactivity. J Immunol. 2000;165:108-13. 37.

39. He R, Geha RS. Thymic stromal lymphopoietin. Ann N Y Acad Sci. 2010 Jan;1183:13-24.

40. Ying S, O'Connor B, Ratoff J, Meng Q, Mallett K, Cousins D, Robinson D, Zhang G, Zhao J, Lee TH, Corrigan C. Thymic stromal lymphopoietin expression is increased in asthmatic airways and correlates with expression of Th2-attracting chemokines and disease severity. J Immunol. 2005;174:8183-90.

41. García-García ML, Calvo C, Moreira A, Cañas JA, Pozo F, Sastre B, Quevedo S, Casas I, Del Pozo V. Thymic stromal lymphopoietin, IL-33, and periostin in hospitalized infants with viral bronchiolitis. Medicine (Baltimore). 2017;96:e6787.

42. Lee HC, Headley MB, Loo YM, Berlin A, Gale M Jr, Debley JS, Lukacs NW, Ziegler SF. Thymic stromal lymphopoietin is induced by respiratory syncytial virus-infected airway epithelial cells and promotes a type 2 response to infection. J Allergy Clin Immunol. 2012;130:1187-1196.e5 
43. Stier MT, Bloodworth MH, Toki S, Newcomb DC, Goleniewska K, Boyd KL, Quitalig M, Hotard AL, Moore ML, Hartert TV, Zhou B, McKenzie AN, Peebles RS Jr. Respiratory syncytial virus infection activates IL-13-producing group 2 innate lymphoid cells through thymic stromal lymphopoietin. J Allergy Clin Immunol. 2016;138:814-824.e11.

44. Malinczak CA, Fonseca W, Rasky AJ, Ptaschinski C, Morris S, Ziegler SF, Lukacs NW. Sex-associated TSLP-induced immune alterations following early-life RSV infection leads to enhanced allergic disease. Mucosal Immunol. 2019;12:969-979.

45. Yagami A, Orihara K, Morita H, Futamura K, Hashimoto N, Matsumoto K, Saito H, Matsuda A. IL-33 mediates inflammatory responses in human lung tissue cells. J Immunol. 2010;185:5743-50.

46. Oboki K, Ohno T, Kajiwara N, Arae K, Morita H, Ishii A, Nambu A, Abe T, Kiyonari H, Matsumoto K, Sudo K, Okumura K, Saito H, Nakae S. IL-33 is a crucial amplifier of innate rather than acquired immunity. Proc Natl Acad Sci U S A. 2010;107:18581-6.

47. Monticelli LA, Sonnenberg GF, Abt MC, Alenghat T, Ziegler CG, Doering TA, Angelosanto JM, Laidlaw BJ, Yang CY, Sathaliyawala T, Kubota M, Turner D, Diamond JM, Goldrath AW, Farber DL, Collman RG, Wherry EJ, Artis D. Innate lymphoid cells promote lung-tissue homeostasis after infection with influenza virus. Nat Immunol. 2011;12:1045-54.

48. Liu J, Wu J, Qi F, Zeng S, Xu L, Hu H, Wang D, Liu B. Natural helper cells contribute to pulmonary eosinophilia by producing IL-13 via IL-33/ST2 pathway in a murine model of respiratory syncytial virus infection. Int Immunopharmacol. 2015;28:337-43.

49. Saravia J, You D, Shrestha B, Jaligama S, Siefker D, Lee GI, Harding JN, Jones TL, Rovnaghi C, Bagga B, DeVincenzo JP, Cormier SA. Respiratory Syncytial Virus Disease Is Mediated by Age-Variable IL33. PLoS Pathog. 2015;11:e1005217.

50. Wu YH, Lai AC, Chi PY, Thio CL, Chen WY, Tsai CH, Lee YL, Lukacs NW, Chang YJ. Pulmonary IL-33 orchestrates innate immune cells to mediate respiratory syncytial virus-evoked airway hyperreactivity and eosinophilia. Allergy. 2020;75:818-830.

51. Lee SA, Kwak MS, Kim S, Shin JS. The role of high mobility group box 1 in innate immunity. Yonsei Med J. 2014;55:1165-76.

52. Harris HE, Raucci A. Alarmin(g) news about danger: workshop on innate danger signals and HMGB1. EMBO reports. 2006; 7:774-8.

53. Chen S, Yu G, Xie J, Tang W, Gao L, Long X, Ren L, Xie X, Deng Y, Fu Z, Liu E. High-mobility group box-1 protein from $\mathrm{CC} 10^{+}$club cells promote type 2 response in the later stage of respiratory syncytial virus infection. Am J Physiol Lung Cell Mol Physiol. 2019;316:L280-L290.

54. Manti S, Harford TJ, Salpietro C, Rezaee F, Piedimonte G. Induction of high-mobility group Box-1 in vitro and in vivo by respiratory syncytial virus. Pediatr Res. 2018;83:1049-1056.

55. Loh Z, Simpson J, Ullah A, Zhang V, Gan WJ, Lynch JP, Werder RB, Sikder AA, Lane K, Sim CB, Porrello E, Mazzone SB, Sly PD, Steptoe RJ, Spann KM, Sukkar MB, Upham JW, Phipps S. HMGB1 amplifies ILC2-induced type-2 inflammation and airway smooth muscle remodelling. PLoS Pathog. 2020;16:e1008651

56. Hou C, Kong J, Liang Y, Huang H, Wen H, Zheng X, Wu L, Chen Y. HMGB1 contributes to allergeninduced airway remodeling in a murine model of chronic asthma by modulating airway inflammation and activating lung fibroblasts. Cell Mol Immunol. 2015;12:409-23.

57. Ma L, Zeng J, Mo B, Wang C, Huang J, Sun Y, Yu Y, Liu S. High mobility group box 1: a novel mediator of Th2-type response-induced airway inflammation of acute allergic asthma. J Thorac Dis. 2015;7:1732-41.

58. Xu M, Dong C. IL-25 in allergic inflammation. Immunol. Rev. 2017, 278, 185-191.

59. Barlow JL, McKenzie AN. IL-25: a key requirement for the regulation of type-2 immunity. BioFactors 2009, 35, 178-182.

60. Yao X, Sun Y, Wang W, Sun Y. Interleukin (IL)-25: Pleiotropic roles in asthma. Respirology 2016, 21, 638-647.

61. Petersen BC, Dolgachev V, Rasky A, Lukacs NW. IL-17E (IL-25) and IL-17RB promote respiratory syncytial virus-induced pulmonary disease. J Leukoc Biol. 2014;95:809-815. 
62. Kaiko GE, Phipps S, Angkasekwinai P, Dong C, Foster PS. NK cell deficiency predisposes to viralinduced Th2-type allergic inflammation via epithelial-derived IL-25. J Immunol. 2010;185:4681-90.

63. Mailliard RB, Son YI, Redlinger R, Coates PT, Giermasz A, Morel PA, Storkus WJ, Kalinski P. Dendritic cells mediate NK cell help for Th1 and CTL responses: two-signal requirement for the induction of NK cell helper function. J Immunol. 2003;171:2366-73.

64. Ichinohe T, Pang IK, Kumamoto Y, Peaper DR, Ho JH, Murray TS, Iwasaki A. Microbiota regulates immune defense against respiratory tract influenza a virus infection. Proc Natl Acad Sci U S A. 2011;108:5354-9.

65. Abt MC, Osborne LC, Monticelli LA, Doering TA, Alenghat T, Sonnenberg GF, Paley MA, Antenus M, Williams KL, Erikson J, Wherry EJ, Artis D. Commensal bacteria calibrate the activation threshold of innate antiviral immunity. Immunity. 2012;37:158-70.

66. Pu Q, Lin P, Gao P, Wang Z, Guo K, Qin S, Zhou C, Wang B, Wu E, Khan N, Xia Z, Wei X, Wu M. Gut Microbiota Regulate Gut-Lung Axis Inflammatory Responses by Mediating ILC2 Compartmental Migration. J Immunol. 2021;207:257-267.

67. Winkler C, Hochdorfer T, Israelsson E, Hasselberg A, Cavallin A, Thorn K, et al. Activation of Group 2 Innate Lymphoid Cells After Allergen Challenge in Asthmatic Patients. J Allergy Clin Immunol 2019; 144:61-9.e7.

68. Constantinides MG. Interactions between the microbiota and innate and innate-like lymphocytes. J Leukoc Biol. 2018;103:409-419.

69. Britanova L, Diefenbach A. Interplay of innate lymphoid cells and the microbiota. Immunol Rev. 2017;279:36-51.

70. Maggi L, Montaini G, Mazzoni A, Rossettini B, Capone M, Rossi MC, Santarlasci V, Liotta F, Rossi O, Gallo O, De Palma R, Maggi E, Cosmi L, Romagnani S, Annunziato F. Human circulating group 2 innate lymphoid cells can express CD154 and promote IgE production. J Allergy Clin Immunol. 2017;139:964-976.e4.

71. Hasegawa K, Linnemann RW, Mansbach JM, Ajami NJ, Espinola JA, Petrosino JF, Piedra PA, Stevenson MD, Sullivan AF, Thompson AD, Camargo CA Jr. The Fecal Microbiota Profile and Bronchiolitis in Infants. Pediatrics. 2016;138:e20160218.

72. Groves HT, Cuthbertson L, James P, Moffatt MF, Cox MJ, Tregoning JS. Respiratory Disease following Viral Lung Infection Alters the Murine Gut Microbiota. Front Immunol. 2018;9:182.

73. Macfarlane S, Woodmansey EJ, Macfarlane GT. Colonization of mucin by human intestinal bacteria and establishment of biofilm communities in a two-stage continuous culture system. Appl Environ Microbiol 2005;71:7483-92.

74. Wang J, Lu H, Yu L, Cheng W, Yan W, Jing X. Aggravation of airway inflammation in RSV-infected asthmatic mice following infection-induced alteration of gut microbiota. Ann Palliat Med. 2021;10:50845097.

75. Li L, Wang F, Liu Y, Gu F. Intestinal microbiota dysbiosis in children with recurrent respiratory tract infections. Microb Pathog. 2019;136:103709.

76. Singh M, Ranjan Das R. Probiotics for allergic respiratory diseases-putting it into perspective. Pediatr Allergy Immunol. 2010;21:e368-76

77. Cardinale F, Lombardi E, Rossi O, Bagnasco D, Bellocchi A, Menzella F. Epithelial dysfunction, respiratory infections and asthma: the importance of immunomodulation. A focus on OM-85. Expert Rev Respir Med. 2020;14:1019-1026.

\section{Figure legends.}

Figure 1. Innate lymphoid cells. A. ILC can be divided into three subsets ILC1, ILC2 and ILC3. ILC1 express the transcription factor T-bet and, in response to IL-12, IL-15, and IL-18, produce IFN- $\gamma$ and TNF$\alpha$. ILC2 express the transcription factor GATA-3 and, in response to the alarmins TSLP, IL-25, HMGB1 and IL-33, secrete IL-4, IL-5 and IL-13. ILC3 express the transcription factor ROR $\gamma$ t and in response to IL-23 and IL-1 $\beta$, release IL-17 and IL-22. B. ILC2 can transdifferentiate into ILC1 or ILC3 in response to IL-1 $\beta$ IL-12 and TGF- $\beta$ and these trans differentiations can be reversed by Th2 cytokines, as IL-4. C. 
Toll-like-receptor-2 ligands can promote the production of the Th2 cytokines IL- 5 and IL-13 by ILC3 cells, which suggests that these cells might be able to differentiate into ILC2 cells.

Figure 2. Following RSV infection, through the release alarmins BECs stimulate ILC2 to release IL-4, IL-5, and IL-13. IL-4 drives Th2 cell differentiation and promotes B cell antibody class switch to IgE. IL-5 is involved in eosinophils recruitment and in their survival enhancement. IL-13 increases goblet cell mucin and airway responsiveness.

Figure 3. Changes in gut microbiota community composition following RSV infection and allergen sensitization in mice. A. RSV infection was associated with significant increase in the relative abundance of Bacteroidetes and a corresponding decrease in Firmicutes . B. In ovalbumin (OVA) sensitized mice, lower abundance of both Bacteroidetes and Firmicutes infection was detected. C. in mice, previously sensitized to OVA, RSV infection was associated with higher abundance of both Bacteroidetes andFirmicutes - Bacteroidetes were most significantly associated with IL-4, IL-5, IL-13, IL-25, and IL-33 production andFirmicutes with IL-33.

\section{Hosted file}

Figure 1.pptx available at https://authorea.com/users/347543/articles/559073-alarminsand-innate-lymphoid-cells-2-activation-a-common-pathogenetic-link-connecting-rsvbronchiolitis-and-later-wheezing-asthma

\section{Hosted file}

Figure 2.pptx available at https://authorea.com/users/347543/articles/559073-alarminsand-innate-lymphoid-cells-2-activation-a-common-pathogenetic-link-connecting-rsvbronchiolitis-and-later-wheezing-asthma

\section{Hosted file}

Figure 3.pptx available at https://authorea.com/users/347543/articles/559073-alarminsand-innate-lymphoid-cells-2-activation-a-common-pathogenetic-link-connecting-rsvbronchiolitis-and-later-wheezing-asthma 